\title{
ASO Author Reflections: Salvage Surgery for Anal Cancer
}

\section{J. A. W. Hagemans, MD}

Department of Surgical Oncology, Erasmus MC Cancer Institute, University Medical Center Rotterdam, Rotterdam, The Netherlands

\section{PAST}

Anal squamous cell carcinoma (SSC) is a relatively rare malignancy with an increasing incidence over the last years. Chemoradiotherapy (CRT) has replaced surgery as treatment for primary anal SCC and is currently standard of care for primary anal SCC. Treatment with CRT leads to preservation of the anal sphincter and a 5-year survival rate up to $80 \%$. Failure of CRT occurs in $20-30 \%$ of the patients, resulting in persistent or recurrent anal SCC. The only available treatment option to achieve durable local control and survival for persistent or recurrent anal SCC is salvage abdominoperineal resection (APR). ${ }^{1}$ Outcomes of salvage APR for anal SCC were previously described in small and heterogenic groups and with variance in treatment protocols. This study evaluated oncologic outcomes and prognostic factors after salvage APR for anal SCC over almost 3 decades with little change in treatment protocol.

\section{PRESENT}

This study confirmed that salvage APR for either persistent or recurrent anal SCC, after failed initial treatment with CRT, can achieve long-term survival and durable local control. ${ }^{2}$ An overall 5-year survival rate of $41.6 \%$ was achieved, and the 5-year local recurrence rate was $44.7 \%$. There was no difference in survival between persistent or

ASO Author Reflections is a brief invited commentary on the article, "Salvage Abdominoperineal Resection for Squamous Cell Anal Cancer: A 30-Year Single-Institution Experience." Ann Surg Oncol. 2018;25:1970-1979.

(C) The Author(s) 2018

First Received: 29 October 2018; Published Online: 9 November 2018

J. A. W. Hagemans, MD

e-mail: j.hagemans@erasmusmc.nl recurrent anal SCC. Important prognostic factors associated with decreased survival are an increased pathological tumour size, positive lymph nodes, and involved resection margins. These prognostic factors have been described previously. Achievement of clear resection margins is the most important prognostic factor, which affects survival and local control. This study confirms the benefit of salvage APR for persistent or recurrent anal SCC after failure of primary treatment with CRT. Surgical treatment of re-recurrence after salvage APR, however, does not appear to be useful.

\section{FUTURE}

The use of salvage APR is well established, but achievement of a higher rate of clear resection margins remains a challenge. Intraoperative radiation therapy could be of value to improve overall survival and local control, but further research is warranted. ${ }^{3}$

The biggest challenge remains systemic treatment of unresectable or metastasized anal SCC. Current systemic chemotherapy schemes often are based on 5-FU and Cisplatin and show poor response and survival rates. ${ }^{4}$ However, a recent promising phase-II trial with combined treatment of docetaxel, cisplatin, and fluorouracil for patients with metastatic or unresectable locally recurrent anal SCC showed a high proportion of complete responses and long-term remissions. ${ }^{5}$ Other randomized, controlled trials, including taxanes, targeted therapy, and immunotherapy, are currently performed and could provide promising treatment strategies in the near future. Further investigation should establish the use of these therapies.

DISCLOSURES The author has no conflict of interest to disclose.

OPEN ACCESS This article is distributed under the terms of the Creative Commons Attribution 4.0 International License (http://crea tivecommons.org/licenses/by/4.0/), which permits unrestricted use, distribution, and reproduction in any medium, provided you give 
appropriate credit to the original author(s) and the source, provide a link to the Creative Commons license, and indicate if changes were made.

\section{REFERENCES}

1. Glynne-Jones R, Nilsson PJ, Aschele C, et al. Anal cancer: ESMOESSO-ESTRO clinical practice guidelines for diagnosis, treatment and follow-up. Eur J Surg Oncol. 2014;40(10):1165-76.

2. Hagemans JAW, Blinde SE, Nuyttens JJ, et al. Salvage abdominoperineal resection for squamous cell anal cancer: a 30-year single-institution experience. Ann Surg Oncol. 2018;25(7):1970-9.
3. Hallemeier CL, You YN, Larson DW, et al. Multimodality therapy including salvage surgical resection and intraoperative radiotherapy for patients with squamous-cell carcinoma of the anus with residual or recurrent disease after primary chemoradiotherapy. Dis Colon Rectum. 2014;57(4):442-8.

4. Eng C, Chang GJ, You YN, et al. The role of systemic chemotherapy and multidisciplinary management in improving the overall survival of patients with metastatic squamous cell carcinoma of the anal canal. Oncotarget. 2014;5(22):11133-42.

5. Kim S, Francois E, Andre T, et al. Docetaxel, cisplatin, and fluorouracil chemotherapy for metastatic or unresectable locally recurrent anal squamous cell carcinoma (Epitopes-HPV02): a multicentre, single-arm, phase 2 study. Lancet Oncol. 2018;19(8):1094-106. 